\title{
Reduction of the depression caused by work stress for teachers: Subjective well-being as a mediator
}

Hung, Chao-Hsiang

National Cheng-Chi University, Taiwan(aka0518@gmail.com)

Lin, Chung-Wei

National Cheng-Chi University, Taiwan (cwlin2012@gmail.com)

Yu, Min-Ning $\bowtie$

National Cheng-Chi University, Taiwan (mnyu@nccu.edu.tw)

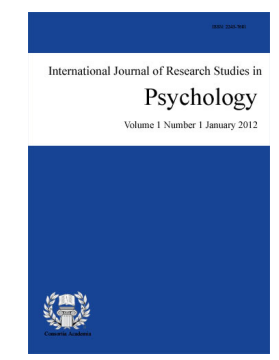

ISSN: $2243-7681$ Online ISSN: 2243-769X

OPEN ACCESS

\section{Abstract}

The mental health of teachers had long been said to bring forth positive outcomes on students' schooling. In the current study, our purpose was to build up a mediation model that could explain how the depression caused by perceived work stress (PWS) would be reduced by lowering subjective well-being (SWB). A total random sample of 1214 teachers was recruited and measured by Subjective Well-Being Scale, Taiwan Depression Scale, and perceived work stress from students, parents, and peers. The whole data were analyzed by ANOVA, Pearson correlations, and structure equation modeling (SEM). Results showed that 1) PWS differed by positions of teachers. 2) PWS from students, parents, and peers had significantly caused Depression. 3) SWB successfully mediated the effects of the PWS and Depression. The current results further provided an empirical proof of how PWS lower teachers' well-being in psychology, social, and emotion of SWB. Our hypothesis of an existed mediation effect had been supported. The current study hoped that the findings would be able to help educational administrators, policy makers, and researchers in protecting teachers' mental health.

Keywords: work-stress; subjective well-being; depression; mediation 


\section{Reduction of the depression caused by work stress for teachers: Subjective well-being as a mediator}

\section{Introduction}

Mental health of teachers is very important because the teacher health may affect the learning environment and mental health of students. Not only long working hours is a kind of work stress but also many kinds of factors like working conditions, the changing education policies of the government, overloaded classes, pupil behavioral problems, lack of educational resources, and poor working conditions are, too (Eres \& Atanasoska, 2011; Kyriacou \& Chien, 2004; Zedan, 2012). However, the perceived work stress is the representative variable to exam teacher's subjective psychological stress. In Taiwan, our previous studies show that teachers with longer working hours have a higher risk of depression and subjective well-being mediated work hours and depression among high school teachers (Yu, Syu, \& Chen, 2010). This study explored the relationship between perceived work stress (PWS) and depression (DEP) among high school, junior high school, and elementary school teachers and the mediating role of subjective well-being (SWB) was also examined. On the other hand, different positions may cause different working conditions and stress of teachers (Eres \& Atanasoska, 2011). We also explore the relationship between positions of teachers and perceived work stress.

\subsection{Work Stress and Depression}

The concept of stress have some elements such as stressors, stress response, stress coping, and stress effects (DeSimon \& Harris, 1998; Matheny \& McCarthy, 2000). The following instructions are teachers' situation. Firstly, there were various stressors of teachers' work, like created curriculum plan and teaching, classroom management, the relationships, the development of professional knowledge, administrative work, and other work requirements. Secondly, when teachers perceived the work requirements over their loading of ability (Karaj \& Rapti, 2013; Kokkinos, 2007; Kyriacou \& Chien, 2004; Kyriacou \& Sutcliffe, 1978; Litt \& Turk, 1985) and induced the physical, cognitive and emotional reactions to stress experience. In addition, the general adaptation syndrome (GAS) described the stress response include alarm reaction, stage of resistance, and stage of exhaustion (Selye, 1951). Thirdly, stress coping is the behavior after stress experience to reduce the stress. Lazarus (1999) pointed out how individuals react to the stress, it called the transactional theory that stress, appraisal, and coping theories (Matthieu \& Ivanoff, 2006). Finally, there were two kinds of results to face a high-strain job. When teachers had control in this job or found some effective coping strategies, the events do not turn into negative effect. Otherwise, if teachers' coping strategies failed or the job was out of control (Karasek, 1979; Van der Doef \& Maes, 1999), they might have physical and psychological damage or even illness.

The teaching is a high-stress occupation (Kokkinos, 2007) and many studies have identified that the teachers work stress were related to many physical and psychological problems (Burke, Greenglass, \& Schwarzer, 1996; Kyriacou, 1987, 2001; Kyriacou \& Chien, 2004). The physical and psychological problem are job dissatisfaction, work strained, anxiety, heart rate, muscle tension, feeling threatened and other adverse conditions (Hopkins and Moss, 1997). Many studies have pointed out that work stress lead burnout (Ashforth \& Lee, 1997; Cooper, Dewe, \& O'Driscoll, 2001; Cordes, Dougherty, \& Blum, 1997; Golembiewski, Boudreau, Goto, \& Murai, 1993; Maslach, Schaufeli, \& Leiter, 2001; Rossi, Perrewe, \& Sauter, 2006) and it might progress depression. According to Tennant,

While depression is the most likely adverse psychological outcome, the range of other possible "psychological" problems include "burnout," alcohol abuse, unexplained physical symptoms, "absenteeism," chronic fatigue and accidents, sick building syndrome and repetitive strain injury (Tennant, 2001, p. 697). 


\subsection{Subjective Well-Being}

Well-being (WB) is a dynamic concept. In the early literature, subjective well-being (SWB) including happiness, life satisfaction, and positive affect (Diener, 1984). Further, subjective well-being should be the level of life satisfaction and felt positive and negative emotional intensity (Diener, Suh, Lucas, \& Smith, 1999). Another point of view, Ryff (1989, 1995), Ryff and Keyes (1995) thought happiness is not just to be happy or positive feelings, but also including autonomy, environmental mastery, personal growth, positive relations with others, purpose in life, and self-acceptance which were called Psychological Well-Being (PsyWB). In addition, Keyes $(2002,2005)$ advanced the third concept that is Social Well-Being (ScoWB). Social well-being is defined as the optimal functioning of society. It is characterized by five dimensions, social integration, social contribution, social coherence, social actualization, social acceptance (Keyes, 1998).

Keyes $(2002,2005)$ and Keyes and Waterman (2003) pointed out the traditional subjective well-being will be regarded as emotional well-being, and they used the classical test theory to measure the mental health include emotional (hedonic approach), psychological, and social well-being (eudaimonic approach). In summary, we use the comprehensive definition to define the subjective well-being (SWB) that includes Emotional Well-Being (EmoWB), Psychological Well-Being (PsyWB), and Social Well-Being (SocWB) to investigate the happiness of teachers.

\subsection{Work Stress, Depression and Subjective Well-Being}

As mentioned above (in section 1.1) work stress related to burnout and depression. This phenomenon of burnout contains emotional exhaustion (lack of emotional resources), depersonalization (indifference to others), low personal accomplishment (negatively evaluate their own behavior and performance) (Maslach, Schaufeli, \& Leiter, 2001). On the contrary, the subjective well-being includes positive feelings, positive relations with others, and autonomy. In additional, Bech et al. pointed out that decreased well-being is the first signal of stress (Bech et al., 2005). Subjective well-being may negatively be related to work stress, burnout, and depression. Past literature on theories of work stress have different definitions such as the work stress is a kind of source from working environment, workers in response to environmental stimuli, or the interaction between environment and workers (Ross \& Altmaier, 1994). The interactional views can let us explore the relationship of workers, environment, and their interaction such as subjective well-being, or coping strategies. In this study, subjective well-being is regarded as a mediator between perceived work stress to depression.

\section{Materials and Methods}

\subsection{Design}

This framework primarily builds on the positive psychology, mental health on the workplace, and the concept of depression. It is hypothesized that the new model of SWB between perceived work stress and depression for Taiwan teachers. We had taken perceived work stress (PWS) as latent IV, subjective well-being (SWB) as a latent mediator, and Depression as latent DV, and four hypotheses were stated as following.

$>\quad$ Hypothesis 1. For Taiwan teachers, PWS has a significantly positive effect on Depression.

$>$ Hypothesis 2. For Taiwan teachers, SWB has a significantly negative effect on Depression.

$>\quad$ Hypothesis 3. For Taiwan teachers, SWB mediates the relationship between PWS and Depression.

$>\quad$ Hypothesis 4. The position of teachers has a significant effect on PWS. 


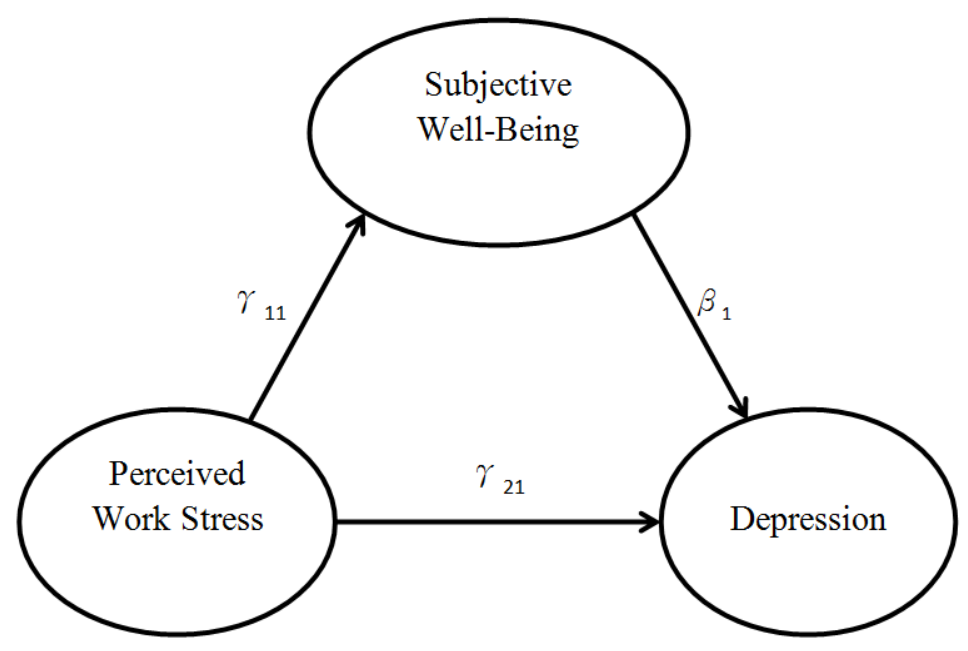

Figure 1. Hypothesized mediated model

\subsection{Participants}

This study involved 1212 Taiwan teachers enrolled in different level schools from primary school (70.0\%), junior high school (20.1\%), high school (6.2\%), and vocational school (3.7\%). The sample included $493(40.7 \%)$ male and $719(59.2 \%)$ female. Of the participants, $58.9 \%$ were the tutor, $13.7 \%$ were the subject teacher, and $26.4 \%$ were with the administrative position. Most part of teachers has the bachelor degree (46.3\%) and master degree $(52.6 \%)$.

\subsection{Measures}

Perceived Work Stress (PWS) - PWS has been used to describe how much loading teachers are suffering. Three items were used to measure the latent variable PWS, including the perceived work stress from students, parents, and peers (Chung, Yu, Syu, Chen, \& Chao, 2013). All items are 4 points Likert's scale ranging from 1 to 4. The higher point means more stress teachers perceived. Three items are reliable and valid, the Cronbach's alpha was .66, and the explained variance was $60.4 \%$.

Subjective Well-Being (SWB) - SWB was measured by short form version of Subjective Well-Being Scale with three factors, including Psychological Well-Being (PsyWB), Social Well-Being (SocWB), and Emotional Well-Being (EmoWB) (Yu, Hsieh, Lin, Chen, \& Tseng, 2011). All items are 4 points Likert's scale ranging from 1 to 4 . The Cronbach's alpha ranging from .63 .86, and the explained variance ranging from 40.2\% 71.1\%.

Depression (DEP) - DEP was measured by Taiwan Depression Scale (TDS), the local scale developed for collecting data of Taiwan people's mental disease (Yu, Huang, \& Liu, 2011; Yu, Liu, \& Li, 2008). There are four factors within TDS, such as Cognitive Depression (CogD), Emotional Depression (EmoD), Physical Depression (PhyD), and Social Depression (SocD). All items are 4 points Likert's scale ranging from 0 to 3. The Cronbach's alpha ranging from .81 .89, and the explained variance ranging from 51.7\% 65.5\%.

\subsection{Data analysis}

The sample has been separated into two parts by random ( $33 \%$ sample, $n=407 ; 67 \%$ sample, $n=804)$. The $33 \%$ sample used in measurement model (Confirmatory Factor Analysis, CFA), the other 67\% sample used in structure model (Structure model and mediation test). Descriptive statistics, ANOVA and correlation estimated using SPSS 21 program, composite reliability (CR) and average variance extracted (AVE) were used to prove the reliability and validity of measurement model. Structure model was used to explaining the relationship and effect among latent variables. Structure equation modeling (SEM) was estimated using the maximum-likelihood 

method in the AMOS 20 program (Arbuckle, 2011).

\section{Results}

\subsection{Effect of Position on Perceived Work Stress}

One of research questions is to figure out the relationship between teachers' position and work stress. The variable "Position" was taken as an independent variable and three kinds of PWS was taken as dependent variables. We employed a one-way (position group) ANOVA to examine the proposed hypothesis of this study. We collected three kinds of teachers' position, including tutors ( $n=696)$, subject teachers $(n=166)$, and administrative teachers $(n=320)$. In these analyzes, we then used these groupings separately as the IV to test its effect on the relevant DV (PWS from students, parents, and peers). The means and standard deviations of all variables are shown in Table 1.

\section{Table1}

The means and SDs of PWS scores in different groups

\begin{tabular}{lllllllll}
\hline \multirow{2}{*}{ Source of PWS } & \multicolumn{2}{l}{ 1.Tutors } & \multicolumn{2}{l}{ 2.Subject teachers } & \multicolumn{2}{l}{ 3.Administrative teachers } & & \\
& $M$ & $S D$ & $M$ & $S D$ & $M$ & $S D$ & $F$ & post hoc \\
\hline Students & .96 & .73 & .81 & .67 & .75 & .67 & $10.33^{* * *}$ & $1>3$ \\
Parents & .82 & .75 & .69 & .78 & .73 & .66 & $3.00 \mathrm{~ns}$. & \\
Peers & .47 & .68 & .43 & .60 & .85 & .76 & $36.55^{* * *}$ & $3>1 ; 3>2$ \\
\hline Note. $n s . p>.05 ; * * *$ & $p<.001$ & & & & &
\end{tabular}

The results revealed that the effect of position on PWS from students was significant, $\mathrm{F}=10.33, p<.001$. Tukey's post hoc test revealed tutors had more PWS from students than administrative teachers. However, the effect of position on PWS from parents was not significant, $\mathrm{F}=3.00, p=.050$. Moreover, the effect of position on PWS from peers was significant, $\mathrm{F}=36.55, p<.001$. Scheffe's post hoc test revealed administrative teachers had more PWS from peers than tutors and subject teachers.

\subsection{Preliminary Analyses}

Means, standard deviations, and zero-order correlations for the 11 measured variables are shown in Table 2. Because the number of the item were not equal in every variable, we used means to represent the mean values. All the means of observed variables ranging from 0.47 3.09, SD ranging from 0.39 .73. Multivariate normality test was used to examine whether the data met the normality assumptions underlying the maximum-likelihood procedure used to test the models in the present study. The results of the multivariate normality test indicated that the data were multivariate normal, multivariate kurtosis was 24 . Therefore, the maximum-likelihood method was appropriate based on Kline's suggestion (Kline, 2005).

\subsection{Measurement Model}

Before a structural model is tested, Anderson and Gerbing (1988) suggested conducting a confirmatory factor analysis to examine whether the measurement model provides an acceptable fit to the data. Once an acceptable measurement model is developed, the structural model can be tested. As suggested by Byrne (2009), $\mathrm{Hu}$ and Bentler (1999), Tucker and Lewis (1973), five fit indices were used to assess goodness of fit for the models: the goodness of fit index (GFI; values $>0.90$ indicate good fit), the comparative fit index (CFI; values $>0.90$ indicate good fit), the Tucker-Lewis Index (TLI; values $>0.90$ indicate good fit), the non-normed fit index (NFI; values $>0.90$ indicate good fit), and the root-mean-square error of approximation (RMSEA; values $<0.08$ indicate good fit).

A test of the measurement model resulted in a relatively good fit to the data $(\chi 2=95.42 * * *, d f=32$ 、 GFI $=.96 \cdot \mathrm{CFI}=.96 \cdot \mathrm{TLI}=.94 \cdot \mathrm{NFI}=.94 \cdot \mathrm{RMSEA}=.070)$. All of the standardized factor loadings of the measured 
Hung, C.-H., Lin, C.-W., \& Yu, M.-N.

variables on the latent variables were statistically significant $(p<.001$, see Table 4$)$. CR of latent variables ranging from .71 .85, AVE ranging from .47 .60, both CR and AVE fit the standard suggest by Fornell and Larcker (1981) and Hair, Black, Babin, and Anderson (2010). Therefore, all of the latent variables appear to have been adequately operationalized by their respective indicators. In addition, correlations among the independent latent variables, the mediator latent variable, and dependent latent variables were all statistically significant $(p$ $<.001$, see Table 5).

Table 2

Means, standard deviations, and zero-order correlations matrix (all sample, $n=1212$ )

\begin{tabular}{|c|c|c|c|c|c|c|c|c|c|c|c|c|}
\hline & $M$ & $S D$ & 1 & 2 & 3 & 4 & 5 & 6 & 7 & 8 & 9 & 10 \\
\hline 1.PWS-students & .88 & .71 & 1 & & & & & & & & & \\
\hline 2.PWS-parents & .78 & .73 & .61 & 1 & & & & & & & & \\
\hline 3.PWS-peers & .57 & .71 & .27 & .31 & 1 & & & & & & & \\
\hline 4.PsyWB & 2.95 & .40 & -.25 & -.24 & -.20 & 1 & & & & & & \\
\hline 5.SocWB & 3.09 & .38 & -.15 & -.17 & -.20 & .56 & 1 & & & & & \\
\hline 6.EmoWB & 2.80 & .54 & -.28 & -.24 & -.21 & .55 & .43 & 1 & & & & \\
\hline 7.CogD & .47 & .39 & .27 & .24 & .24 & -.49 & -.40 & -.47 & 1 & & & \\
\hline 8.EmoD & .91 & .45 & .36 & .31 & .26 & -.42 & -.32 & -.46 & .70 & 1 & & \\
\hline 9.BioD & .91 & .49 & .29 & .28 & .25 & -.36 & -.30 & -.42 & .55 & .69 & 1 & \\
\hline 10.SocD & .75 & .57 & .21 & .21 & .25 & -.37 & -.34 & -.44 & .54 & .52 & .56 & 1 \\
\hline
\end{tabular}

Note. All values of correlation are significant $(p<.001)$.

\section{Table 3}

Model fit indices

\begin{tabular}{cccc}
\hline Indices & $\begin{array}{c}\text { measurement } \\
\text { model }\end{array}$ & structural model & criteria \\
\hline $\mathrm{N}$ & 404 & 804 & \\
$\chi 2$ & $95.42^{* * *}$ & $190.39 * * *$ & \\
$\mathrm{df}$ & 32 & 32 & \\
\hline $\mathrm{GFI}$ & .955 & .954 & $>.90$ \\
$\mathrm{CFI}$ & .958 & .947 & $>.90$ \\
$\mathrm{TLI}$ & .941 & .926 & $>.90$ \\
$\mathrm{NFI}$ & .939 & .937 & $>.90$ \\
RMSEA & .070 & .079 & $<.08$ \\
\hline
\end{tabular}

\section{Table 4}

Factor loadings for the measurement model (33\% sample, $n=407)$

\begin{tabular}{|c|c|c|c|c|c|}
\hline Factor and Item & $\begin{array}{l}\text { Standardized } \\
\text { factor loading }\end{array}$ & $S E$. & $t$ & $A V E$ & $C R$ \\
\hline Perceived Work Stress (PWS) & & & & .47 & .71 \\
\hline from students & .77 & & & & \\
\hline from parents & .81 & .105 & 10.28 & & \\
\hline from peers & .40 & .076 & 7.06 & & \\
\hline \multicolumn{6}{|l|}{ Subjective Well-Being (SWB) } \\
\hline PsyWB & .74 & & & .53 & .77 \\
\hline SocWB & .65 & .073 & 10.95 & & \\
\hline EmoWB & .79 & .116 & 11.53 & & \\
\hline \multicolumn{6}{|l|}{ Depression (DEP) } \\
\hline $\operatorname{Cog} \mathrm{D}$ & .79 & & & 60 & .85 \\
\hline EmoD & .89 & .072 & 18.46 & & \\
\hline BioD & .74 & .079 & 15.48 & & \\
\hline SocD & .65 & .098 & 13.15 & & \\
\hline
\end{tabular}

Note. All standardized factor loading are significant $(p<.001)$. 
Reduction of the depression caused by work stress for teachers: Subjective well-being as a mediator

Table 5

Correlations matrix for the measurement model (33\% sample, $n=407)$

\begin{tabular}{lccc}
\hline \multicolumn{1}{c}{ Latent Variables } & 1 & 2 & 3 \\
\hline 1.Perceived Work Stress (PWS) & 1 & & \\
2.Subjective Well-Being (SWB) & -.39 & 1 & 1 \\
3.Depression (DEP) & .48 & -.69 & \\
\hline Note. All values of correlation are significant $(p<.001)$. & &
\end{tabular}

\subsection{Structural Model for Testing Mediated Effects}

We had taken Perceived Work Stress (PWS) as latent IV, Subjective Well-Being (SWB) as latent mediator, and Depression (DEP). The results showed a good fit of the model to the data $(\chi 2=190.39 * * *$, df $=32$, GFI $=.95, \mathrm{CFI}=.95, \mathrm{TLI}=.92, \mathrm{NFI}=.94, \mathrm{RMSEA}=.079)$. Path effect is frequently referred to as direct effect. All the effect size of structural paths were medium $(\gamma 11=-.37, \beta 1=-.60, \gamma 21=.19)$ and significant $(p<.001$, see Table 6).

MacKinnon, Lockwood, Hoffmann, West, and Sheets (2002) assessed many approaches to examine mediation considering Type I error and statistical power. Found the most often used strategy by Baron and Kenny (1986) has the least power (both $\gamma 11$ and $\beta 1$ have to be significant). Then, many studies using this approach have relied on the Sobel test (1982) to examine the significance of mediation effect $(\gamma 11 * \beta 1$ have to be significant). However, there is evidence that the distribution of mediation effect is not normal (Bollen \& Stine, 1990; MacKinnon \& Dwyer, 1993; Stone \& Sobel, 1990), and the utilization of a significance test, such as the Sobel test, which assumes a normal distribution when examining the mediation effect, is not appropriate. Most recently, Shrout and Bolger (2002) suggest the bootstrap method (Efron \& Tibshirani, 1993) can be a better way to examine mediation. The bootstrap method acquires $95 \%$ confidence intervals (CI) for the indirect effect of the resampling procedure. Based on the central limit theorem, bootstrap method is robust even the distribution of mediation effect is not normal.

As Shrout and Bolger's (2002) suggestion, if the 95\% CI for the estimates of the indirect effects based on these 5000 indirect effect estimates does not include zero, then it can be concluded that the indirect effect is statistically significant at the .05 level. Therefore, after the structural models were examined through the AMOS 20 program, the bootstrap procedure was used to test whether or not the indirect effects were statistically significant.

Mediation effect is frequently referred to as indirect effect $(\gamma 11 * \beta 1)$ was .22 . The $95 \%$ CI for the estimates of the indirect effects ranging from .16 .28 does not include zero, then it can be concluded that the indirect effect is statistically significant at the .05 level. For Taiwan teachers, SWB plays a role as mediator between PWS and DEP. The total effect is the summation of direct effect and indirect effect $(\gamma 21+\gamma 11 * \beta 1)$, the total effect was .41 , the $95 \% \mathrm{CI}$ for total effects ranging from .32 .50 does not include zero, the total effect is statistically significant at the .05 level. The results of the structure model shown the theory model can explain depression well for Taiwan teachers. As above, hypotheses 1 3 are supported. In addition, according to Baron and Kenny (1986), because the direct effect is still significant, our model is partial mediation, shown there may be other effective mediators can be taken into consideration in the future.

\section{Table 6}

Bootstrap Analysis of Structural Model (67\% sample, $n=804)$

\begin{tabular}{ccccccc}
\hline & Direct effect & \multicolumn{2}{c}{ Indirect effect } & \multicolumn{2}{c}{ Total effect } \\
\hline$\gamma 11$ & $\beta 1$ & $\gamma 21$ & $\gamma 11 * \beta 1$ & $95 \% \mathrm{CI}$ & $\gamma 21+\gamma 11 * \beta 1$ & $95 \% \mathrm{CI}$ \\
$-.37 * * *$ & $-.60 * * *$ & $.19 * * *$ & .22 & $.16 \sim .28$ & .41 & $.32 \sim .50$ \\
\hline Note. $* * * p<.001$ & & &
\end{tabular}




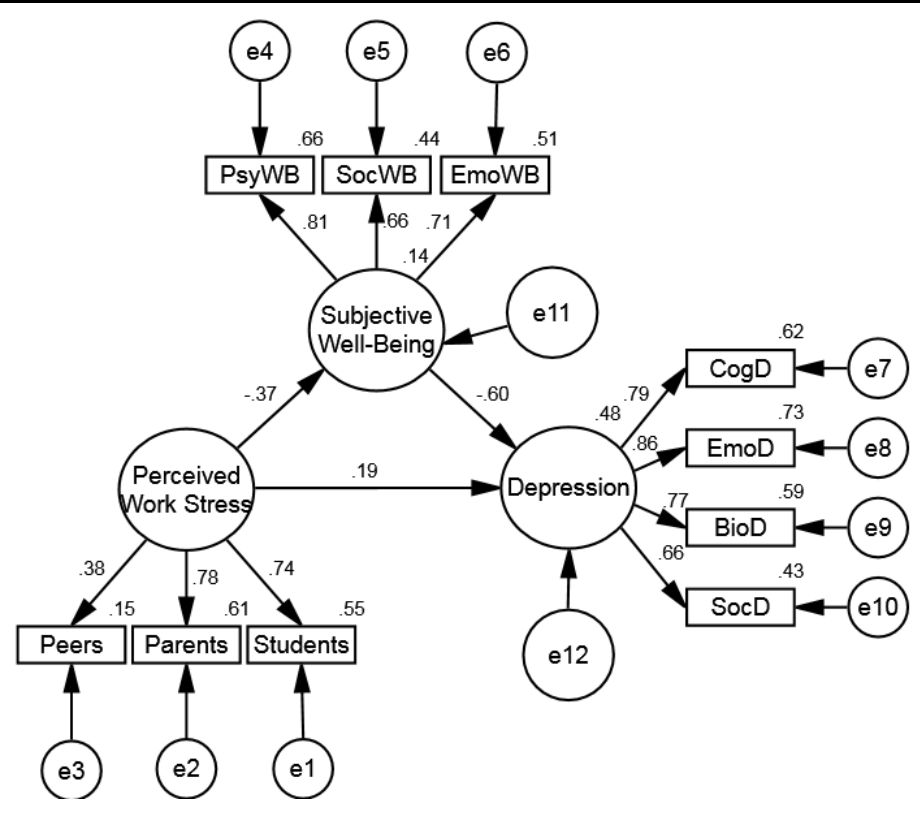

Figure 2. Full model

\section{Conclusions}

In this study, we use the structured equation modeling in providing the relation between the perceived work stress (PWS), subjective well-being (SWB), and depression (DEP) for Taiwan teachers. The result of structure model shown that the subjective well-being is a mediator between perceived work stress and depression. It indicates that high perceived work stress does not influence teacher's depression level directly, and it depends on teacher's subjective well-being level. For example, a teacher who has high perceived work stress with high subjective well-being has low depression level. Conversely, a teacher who has high perceived work stress with low subjective well-being has high depression level. It also indicates that the level of subjective well-being can decrease Taiwan teachers' depression level. In addition, according to Baron and Kenny (1986), two paths of direct effect is still significant, one mediation path in our model are partial mediation, shown there may be other effective mediators can be taken into consideration in the future such us coping strategies, personality traits, interpersonal relationship, work seniority (Katz \& Kahn, 1978), and job control (Karasek, 1979).

How can we help teachers? Even though that reduce teachers' workload can decline their working stress, but Taiwan teachers' workload cannot be reduced immediately by policy, it might take a long time. Fortunately, according to our study, teachers' working stress is not always annexed to depression, if teachers have high subjective well-being level. We suggest that schools and teachers should pay attention to enhancing their subjective well-being such as healthy behavior (regular leisure activities and physical activity), appraisal support from other teachers and parents (teach teachers to give positive feedback and support each other), and practice mindfulness (Brown \& Ryan, 2003; Carmody \& Baer, 2008; Yu, Chung, Chen, Syu, \& Chao, 2011). Their subject positive attitude can help fight depression. In addition, teachers can improve their ability of stress awareness and coping strategies, because the good coping strategies skills can help teacher to face stress healthily (Penedo et al., 2004). Schools and the government should create a positive and healthy working environment such as not only value the physical health but also pay attention to the psychological health of teachers, notice the teacher who has the signs of burnout, and provides stress coping strategies of training or workshops.

Acknowledgements: This work was supported by the Taiwan National Science Council Project No. 102-2410-H-004-191-SS2. 


\section{References}

Anderson, J. C., \& Gerbing, D. W. (1988). Structural equation modeling in practice: A review and recommended two-step approach. Psychological Bulletin, 103(3), 411-423. http://dx.doi.org/10.1037/0033-2909.103.3.411

Arbuckle, J. L. (2011). IBM SPSS Amos 20 user's guide. Armonk, NY: IBM.

Ashforth, B. E., \& Lee, R. T. (1997). Burnout as a process: Commentary on Cordes, Dougherty, and Blum. Journal of Organizational Behavior, 18(6), 703-708. http://dx.doi.org/10.1002/(SICI)1099-1379(199711)18:6<703::AID-JOB847>3.0.CO;2-1

Baron, R. M., \& Kenny, D. A. (1986). The moderator-mediator variable distinction in social psychological research: Conceptual, strategic, and statistical considerations. Journal of Personality and Social Psychology, 51(6), 1173. http://dx.doi.org/10.1037/0022-3514.51.6.1173

Bech, P., Andersen, M. B., Bech-Andersen, G., Tønnesen, S., Agnarsdottir, E., \& Borg, V. (2005). Work-related stressors, depression and quality of life in Danish managers. European Psychiatry, 20, S318-S325. http://dx.doi.org/10.1016/S0924-9338(05)80183-X

Bollen, K. A., \& Stine, R. (1990). Direct and indirect effects: Classical and bootstrap estimates of variability. Sociological methodology, 20(1), 15-140. http://dx.doi.org/10.2307/271084

Brown, K. W., \& Ryan, R. M. (2003). The benefits of being present: mindfulness and its role in psychological well-being. Journal of personality and social psychology, 84(4), 822-848. http://dx.doi.org/10.1037/0022-3514.84.4.822

Burke, R. J., Greenglass, E. R., \& Schwarzer, R. (1996). Predicting teacher burnout over time: Effects of work stress, social support, and self-doubts on burnout and its consequences. Anxiety, Stress, and Coping, 9(3), 261-275. http://dx.doi.org/10.1080/10615809608249406

Byrne, B. M. (2009). Structural equation modeling with AMOS: Basic concepts, applications, and programming. CRC Press.

Carmody, J., \& Baer, R. A. (2008). Relationships between mindfulness practice and levels of mindfulness, medical and psychological symptoms and well-being in a mindfulness-based stress reduction program. Journal of behavioral medicine, 31(1), 23-33. http://dx.doi.org/10.1007/s10865-007-9130-7

Chung, P. C., Yu, M. N., Syu, J. J., Chen, P. L., \& Chung, P. C. (2013). From languishing to flourishing: Exploration of the types of teachers' mental health statuses and predictors of teachers' mental health. Bulletin of Educational Psychology, 44(3), 629-646.

Cooper, C. L., Dewe, P. J., \& O'Driscoll, M. P. (2001). Organizational stress: A review and critique of theory, research, and applications. SAGE Publications.

Cordes, C. L., Dougherty, T. W., \& Blum, M. (1997). Patterns of burnout among managers and professionals: A comparison of models. Journal of Organizational Behavior, 18(6), 685-701. http://dx.doi.org/10.1002/(SICI)1099-1379(199711)18:6<685::AID-JOB817>3.0.CO;2-U

Desimone, R., \& Harris, D. (1998). Human resource development (2nd ed.). USA: Dryden Press.

Diener, E. (1984). Subjective well-being. Psychological Bulletin, 95, 542-575. http://dx.doi.org/10.1037/0033-2909.95.3.542

Diener, E. D., Suh, E. M., Lucas, R. E., \& Smith, H. L. (1999). Subjective well-being: Three decades of progress. Psychological Bulletin, 125, 276-302. http://dx.doi.org/10.1037/0033-2909.125.2.276

Efron, B., \& Tibshirani, R. (1993). An introduction to the Bootstrap. New York: Chapman \& Hall. http://dx.doi.org/10.1007/978-1-4899-4541-9

Eres, F., \& Atanasoska, T. (2011). Occupational stress of teachers: A comparative study between Turkey and Macedonia. International Journal of Humanities and Social Science, 1(7), 59-65.

Fornell, C., \& Larcker, D. F. (1981). Structural equation models with unobservable variables and measurement error: Algebra and statistics. Journal of Marketing Research, 18(3), 382-388. http://dx.doi.org/10.2307/3150980

Golembiewski, R. T., Boudreau, R., Goto, K., \& Murai, T. (1993). Transnational perspectives on job burnout: Replication of phase model results among Japanese respondents. The International Journal of 
Organizational Analysis, 1(1), 7-27. http://dx.doi.org/10.1108/eb028781

Hair, J. F., Black, W. C., Babin, B. J., \& Anderson, R. E. (2010). Multivariate data analysis: A global perspective (7th ed.). Upper Saddle River, NJ: Pearson Prentice Hall.

Hopkins, W. S., Hoffman, S. Q., \& Moss, V. D. (1997). Professional development schools and preservice teacher stress. Action in Teacher Education, 18(4), 36-46. http://dx.doi.org/10.1080/01626620.1997.10463362

Hu, L. T., \& Bentler, P. M. (1999). Cutoff criteria for fit indexes in covariance structure analysis: Conventional criteria versus new alternatives. Structural Equation Modeling: A Multidisciplinary Journal, 6(1), 1-55. http://dx.doi.org/10.1080/10705519909540118

Karaj, S., \& Rapti, E. (2013). Teacher job stress in Albania: Examining the role of students' classroom disruptive behavior and other factors in the school context. Problems of education in the 21St century, 54, 14-21.

Karasek, R. (1979). Job demands, job decision latitude, and mental strain: Implications for job redesign. Administrative Science Quarterly, 24, 285-306. http://dx.doi.org/10.2307/2392498

Katz, D., \& Kahn, R. L. (1978). The social psychology of organizations (2nd ed.). New York: John Wiley \& Sons.

Keyes, C. L. M. (1998). Social well-being. Social Psychology Quarterly, 61, 121-140. http://dx.doi.org/10.2307/2787065

Keyes, C. L. M. (2002). The mental health continuum: From languishing to flourishing in life. Journal of Health and Social Behavior, 43(2), 207-222. http://dx.doi.org/10.2307/3090197

Keyes, C. L. M. (2005). Mental illness and/or mental health? Investigating axioms of the complete state model of health. Journal of Consulting and Clinical Psychology, 73(3), 539-548. http://dx.doi.org/10.1037/0022-006X.73.3.539

Keyes, C. L., \& Waterman, M. B. (2003). Dimensions of well-being and mental health in adulthood. In M. H. Bornstein, L. Davidson, C. L. M. Keyes, \& Moore, A Kristin (Eds.), Well-being: Positive development across the life course (pp. 477-497). Mahwah, NJ: Lawrence Erlbaum Associates.

Kline, R. B. (2005). Principles and practice of structural equation modeling (2nd ed.). New York, NY: Guilford.

Kokkinos, C. M. (2007). Job stressors, personality and burnout in primary school teachers. British Journal of Educational Psychology, 77(1), 229-243. http://dx.doi.org/10.1348/000709905X90344

Kyriacou, C. (1987). Teacher stress and burnout: An international review. Educational Research, 29(2), 146-152. http://dx.doi.org/10.1080/0013188870290207

Kyriacou, C. (2001). Teacher stress: Directions for future research. Educational Review, 53, 27-35. http://dx.doi.org/10.1080/00131910120033628

Kyriacou, C., \& Chien, P. (2004). Teacher stress in Taiwanese primary schools. Journal of Educational Enquiry, $5(2), 86-104$.

Kyriacou, C., \& Sutcliffe. (1978). Model of teacher stress. Educational Studies, 4, 4-6. http://dx.doi.org/10.1080/0305569780040101

Lazarus, R. S. (1999). Stress and emotion: A new synthesis. New York: Springer.

Litt, M. D., \& Turk, D. C. (1985). Sources of stress and dissatisfaction in experienced high school teachers. Journal of Educational Research, 78(3), 178-185. http://dx.doi.org/10.1080/00220671.1985.10885596

MacKinnon, D. P., \& Dwyer, J. H. (1993). Estimating mediated effects in prevention studies. Evaluation Review, 17(2), 144-158. http://dx.doi.org/10.1177/0193841X9301700202

MacKinnon, D. P., Lockwood, C. M., Hoffman, J. M., West, S. G., \& Sheets, V. (2002). A comparison of methods to test mediation and other intervening variable effects. Psychological Methods, 7(1), 83-104. http://dx.doi.org/10.1037/1082-989X.7.1.83

Maslach, C., Schaufeli, W. B., \& Leiter, M. P. (2001). Job burnout. Annual Review of Psychology, 52(1), 397-422. http://dx.doi.org/10.1146/annurev.psych.52.1.397

Matheny, K. B., \& McCarthy, C. J. (2000). Write your own prescription for stress. Oakland, CA: New Harbinger Publications.

Matthieu, M. M., \& Ivanoff, A. (2006). Using stress, appraisal, and coping theories in clinical practice: Assessments of coping strategies after disasters. Brief Treatment and Crisis Intervention, 6(4), 337-348. http://dx.doi.org/10.1093/brief-treatment/mhl009 
Reduction of the depression caused by work stress for teachers: Subjective well-being as a mediator

Penedo, F. J., Dahn, J. R., Molton, I., Gonzalez, J. S., Kinsinger, D., Roos, B. A., ..., \& Antoni, M. H. (2004). Cognitive-behavioral stress management improves stress-management skills and quality of life in men recovering from treatment of prostate carcinoma. Cancer, 100(1), 192-200. http://dx.doi.org/10.1002/cncr.11894

Ross, R. R., \& Altmaier, E. M. (1994). Intervention in occupational stress. Thousand Oaks, CA: Sage.

Rossi, A. M., Perrewe, P. L., \& Sauter, S. L. (2006). Stress and quality of working life: Current perspectives in occupational health. IAP.

Ryff, C. D. (1989). Happiness is everything, or is it? Explorations on the meaning of psychological well-being. Journal of Personality and Social Psychology, 57, 1069-1081. http://dx.doi.org/10.1037/0022-3514.57.6.1069

Ryff, C. D. (1995). Psychological well-being in adult life. Current Direction in Psychological Science, 4, 99-104. http://dx.doi.org/10.1111/1467-8721.ep10772395

Ryff, C. D., \& Keyes, C. L. M. (1995). The structure of psychological well-being revisited. Journal of Personality and Social Psychology, 69, 719-727. http://dx.doi.org/10.1037/0022-3514.69.4.719

Selye, H. (1951). The general adaptation syndrome and the diseases of adaptation. The American Journal of Medicine, 10(5), 549-555. http://dx.doi.org/10.1016/0002-9343(51)90327-0

Shrout, P. E., \& Bolger, N. (2002). Mediation in experimental and nonexperimental studies: new procedures and recommendations. Psychological Methods, 7(4), 422-445. http://dx.doi.org/10.1037/1082-989X.7.4.422

Sobel, M. E. (1982). Asymptotic confidence intervals for indirect effects in structural equation models. Sociological Methodology, 13, 290-313. http://dx.doi.org/10.2307/270723

Stone, C. A., \& Sobel, M. E. (1990). The robustness of estimates of total indirect effects in covariance structure models estimated by maximum. Psychometrika, 55(2), 337-352. http://dx.doi.org/10.1007/BF02295291

Tennant, C. (2001). Work-related stress and depressive disorders. Journal of Psychosomatic Research, 51(5), 697-704. http://dx.doi.org/10.1016/S0022-3999(01)00255-0

Tucker, L. R., \& Lewis, C. (1973). A reliability coefficient for maximum likelihood factor analysis. Psychometrika, 38(1), 1-10. http://dx.doi.org/10.1007/BF02291170

Van der Doef, M., \& Maes, S. (1999). The job demand-control (-support) model and psychological well-being: A review of 20 years of empirical research. Work \& Stress, 13(2), 87-114. http://dx.doi.org/10.1080/026783799296084

Yu, M. N., Chung, P. C., Chen, P. L., Syu, J. J., \& Chao, P. C. (2011) Subjective well-being as a mediator among the relationships of healthy behavior, appraisal support, and depression in Taiwan teachers. Journal of Health Promotion and Health Education Contents, 35, 23-48.

Yu, M. N., Hsieh, J. C., Lin, S. Y., Chen, P. L., \& Tseng, H. C. (2011). Confirmatory study of model of teachers' subjective well-being. Psychological Testing, 58(1), 55-85.

Yu, M. N., Huang, H. Y., \& Liu, Y. J. (2011). The development and psychometric study of Taiwan Depression Scale. Psychological Testing, 58(3), 479-500.

Yu, M. N., Liu, Y. J., \& Li, R. H. (2008). The practical usage of cutoff score in the Taiwanese Depression Scale. Journal of Educational Research and Development, 4(4), 231-258.

Yu, M. N., Syu, J. J., \& Chen, P. L. (2010). The relationship between working hours and depression of elementary and secondary school teachers: Perspective of subjective well-being. Bulletin of Educational Psychology, 42(2), 229-252.

Zedan, R. (2012). Stress and coping strategies among elementary schools teachers in Israel. Universal Journal of Education and General Studies, 1(9), 265-278. 
Hung, C.-H., Lin, C.-W., \& Yu, M.-N. 